\title{
A Comparison of Conversational Patterns Between Mothers and their Down Syndrome and Normal Infants
}

\author{
Gerald Mahoney \\ Kathleen Robenalt
}

\begin{abstract}
The purpose of this study was to compare conversational patterns between mothers and Down syndrome children with those botween mothers and normally developing children. Patterns of maternal interaction with 2- and 3-year-old Down syndrome children and a developmentally matched sample of nonretarded children were analyzed with the turn-taking paradigm developed by Kaye \& Charney $(1980,1981)$. The results of this comparison indicated that mothers of Down syndrome children were more dominant and their children less active communication partners than their normal counterparts. Post hoc analyses suggested that mothers of Down syndrome children may be more directive as a result of their efforts to induce their children to increase their activity level. Implications of these findings for children's language development were discussed.
\end{abstract}

Delayed language development is among the most serious problems associated with moderate to severe levels of mental retardation. In general, the language functioning achieved by this population is often lower than might be expected based upon concurrent indices of cognitive functioning. Even though the assessed cognitive status of mentally retarded children is correlated highly to their level of language functioning (Mahoney $\&$ Snow, 1983), comparisons between groups of normal and mentally retarded children that are matched according to level of mental development indicate that mentally retarded children have significantly lower levels of language functioning than normal children (Rondal, 1978a; Mahoney, Glover, \& Finger, 1981).

At least two hypotheses have been proposed to explain this phenomenon. The first is that there are innate characteristics which interfere with the acquisition of lan- guage. Mentally retarded children may either have deficiencies in those mental structures involved in language acquisition (Lenneberg, 1967) or have a lag in the development of the neurological maturity required for language learning. The second hypothesis is that there may be deficiencies in the quality of language and/or communicative interaction between mothers, or other primary language agents, and mentally retarded children which interfere with children acquiring language (Mahoney, 1975; Mahoney \& Seeley, 1976). Since no investigations have been reported that are directly related to the first hypothesis, the degree to which innate characteristics of the mentally retarded can explain their delayed language growth is uncertain. However, several studies related to the communicative interaction hypothesis have been reported. To date, the results from these studies have been equivocal, because most have been predominantly de- 
scriptive and have not been linked clearly to theories of language interaction.

There are two alternative conceptualizations of how the process of language interaction is related to language development. The first is that the critical dimension of language interaction is related to the structural characteristics of the language that mothers use while speaking to their children (Snow, 1977). This theory is based upon informationprocessing notions of language learning, according to which children's facility at learning language is related to the match between the linguistic features of their language input and their current level of communicative competence (Shatz, 1981). The second theory is that early conversations and other interactions between mothers and their children are the critical foundation for language learning (Bruner, 1983, Wells, 1981). This notion is based upon communication models of language development which view language as evolving from lower forms of communication and consider the essential condition for early language learning to be children's active and frequent participation in preverbal communicative exchanges (Bruner, 1974/75). As children develop communication proficiency, it is thought that they begin to perceive the inadequacy of their nonverbal and idiosyncratic communicative devices and strive to attain more conventional forms of communicating.

Those who have investigated the interaction between mothers and mentally retarded children have generally found that the structural features of maternal language are commensurate with children's level of language and/or developmental competence. When mothers and their mentally retarded children are compared with mothers and normally developing children and the children are matched with each other on language measures such as MLU or mental development measures such as Developmental Age, the language used by all mothers is comparable in terms of semantic and syntactic complexity (Rondal, 1978b; Cunningham, Reuler, Blackwell, \& Deck, 1981). Mothers of mentally retarded children, however, have been reported to be more directive (Cunningham et al., 1981), to talk more frequently, and to be less attuned to their children's conversational topics (Petersen \& Sherrod, 1982). These findings suggest that, although mothers of mentally retarded children provide appropri- ate language input, they differ somewhat from mothers of normal children in the manner in which they converse with their children.

Only one study has been reported that has attempted to link language interaction to the rate of development achieved by mentally retarded children. Mahoney (1983) reported that differences in the rate of language development achieved by one- to three-yearold mentally retarded children were unrelated to several structural parameters of maternal language but were related to the manner in which mothers and their children communicated with each other. Mothers who were more communicatively responsive to their children's communicative behavior generally had children who were more responsive to their mothers' communication and were functioning at higher levels of communicative competence than other children. The design of this study, however, precluded interpreting these results as indicating either that mother-child communication style is causally related to children's language growth or that deficiencies in mother-child communication can explain the language delay observed among mentally retarded children.

The purpose of this study is to explore further the differences in conversational patterns between mothers and young mentally retarded children compared to those between mothers and their normal children. The study has been designed to yield data which will have direct implications for theories of language interaction based upon communication models of language development. The primary scheme for analyzing interaction is the turntaking paradigm developed by Kaye and Charney (1980, 1981). This classification system has several features that make it particularly desirable for investigating early conversations. First, all behaviors of both children and their mothers are treated as a part of the conversation. This is compatible with the theory that nonverbal communication, and even noncommunicative behavior, are the bases for the development of children's communication. Second, since the behavior of both mothers and their children are coded according to this system, this classification scheme allows us to assess the relationship between mother and child interactive behavior. Third, this classification scheme characterizes the conversational role 
of each interactive behavior as either a mand (directive), a response, or a response-mand. These roles appear to be the very characteristics that both distinguish maternal interaction with mentally retarded children and characterize the communicative features that appear to constitute effective interaction. The matched sample design for this study in which mentally retarded children are matched with nonretarded children on both language and developmental competence, and in which mothers are matched on several socioeconomic indices that are thought to be related to language interaction, enables us to isolate conversational characteristics that are related uniquely to mental retardation associated with Down syndrome.

\section{METHOD.}

\section{Subjects}

Two groups of infants and their mothers were the subjects for this study. A group of 20 dyads in which the infants had Down syndrome (DS) was randomly selected from a larger sample of dyads who had participated in another study involving Down syndrome infants and their mothers (Mahoney, Finger, \& Powell, 1985). These infants had been involved in varying degrees with intervention programs up to the time of their participation in that study. Documented evidence of Trisomy 21 was available for all of the infants. The Down syndrome infants included two sub-groups (each $\mathfrak{n}=10$ ) which had average chronological ages of 24 (younger) and 36 months (older), average developmental ages (DA) as measured by the Bayley Mental Developmental Scale of $\mathbf{1 5 . 5}$ and 19.4 months, and average expressive language ages as measured by the REEL of 13.7 and 17.0 months. The Younger DS infants consisted of four girls and 6 boys, while the Older infants consisted of six boys and four girls.

The second group of dyads included 20 normally developing infants and their mothers (N). Normal infants had been selected so that they would be equivalent to the DS infants on the following characteristics: developmental age plus or minus one month, expressive language age plus or minus two months, age of mother plus or minus three years, years of education of the mothers, and sex of the infants. These subjects were ob- tained primarily through university subject pools (e.g., individuals who had indicated their willingness to participate in a study of child development). Of a total of 27 infants tested, seven were eliminated because test results indicated they could not be matched suitably with the DS group. The final group of normal infants consisted of two subgroups, each having five boys and five girls, that were matched to the Younger and Older DS groups. These subgroups had average chronological ages of 14.8 and 16.5 months, average developmental ages of 15.8 and 19.4 months, and average expressive language ages of 13.1 and 18.2 months. Attempts were also made to match the $N$ and DS groups on marital status of the parents and family income level. There were no significant group differences in developmental age, expressive language age, sex of the infants, and age of the mothers ( 32.9 vs 31.5 years). The mothers of the normal infants had more years of education than the mothers of the Down Syndrome infants (15.7 yrs. versus 13.6 yrs.) $(F(1,36)=10.24, p<.01)$.

\section{PROCEDURES}

All mothers were contacted by telephone to solicit their participation. They were informed that the purpose of the study was to identify factors that influence the development of play and communication in young infants. All data were collected in the subjects' homes, usually within one session. The Bayley Mental Development Scale (Bayley, 1969) was administered to the infants by a research assistant who had been trained as a licensed psychologist. Another investigator, a clinically certified speech/language pathologist, administered the Receptive-Expressive Emergent Language Scale (REEL) (Bzoch \& League, 1970), an assessment procedure which involves interviewing mothers to obtain information relative to their child's current language functioning. Data sessions were scheduled so that the infants were functioning near optimal levels. All standardized tests were administered according to the procedures recommended in the respective test manuals.

Mothers and their infants were videotaped for 20 minutes while they played together. A point-source microphone was placed on the floor near the dyad to yield a clear audio-re- 
cording. The play session was conducted in the living rooms, which were not altered except to remove objects and toys distracting to the infants. Mothers were provided with a set of age-appropriate toys that consisted of a toy bus with moveable figures, wooden blocks, a play stove with accompanying related pieces, stacking rings, nesting cubes, a xylophone, picture books, and a pull toy. Mothers were instructed to play with their children as they normally do, using only the provided toys. They were not restricted to playing only with toys, nor were they told to remain in any one position.

The first 200 consecutive turns for each dyad were transcribed from the videotapes according to procedures developed by Kaye and Charney $(1980,1981)$. A turn was defined as any behavior produced by one person during the course of interaction. A turn could be either a single utterance with accompanying gestures, two or more utterances strung together without a pause of at least one second between them, or nonverbal acts alone. Each turn was identified according to the speaker (mother or child), modality (verbal, nonverbal communication, meaningless vocalization, action), and type of turn. The turn type was one of four categories: mand (M)a turn which requires a response and to which it would be rude not to respond in normal adult discourse; response (R)-a turn which is a response to the other person; response-mand (RM) -a turn which is both a response to a previous turn and simultaneously requires a response from the other person; unlinked (U) - a turn that cannot be classified in the three preceding categories.

Two coders were trained for a total of 15-20 hours using videotape recordings of play between mothers and normal infants and between mothers and mentally retarded infants. One coder was trained to identify turns. Reliability (Agreements/Agreements + Disagreements $\times 100$ ) between the coder and the investigator for identifying and segmenting turns in the interactions was $85 \%$ for $10 \%$ of the total observations. Another coder who was trained to identify turn types achieved $86 \%$ agreement with the investigator for classifying turn types on $10 \%$ of the total observations.

Three components of turns were transcribed on coding sheets. The first was the person who produced the turn (e.g., mother or infant). Second, the turn type was classified as either a mand (M), a response (R), a response-mand (RM), or unlinked (U). Third, each turn was classified according to its modality as either verbal (V) (spoken turn involving intelligible words or sounds which substitute for words, i.e., "vroom-vroom" when pushing a car), nonverbal (NV) (pointing to a toy as if to say "Get the toy" or pointing to a picture as if to say "What's that?"), vocal (Vo) (non-meaningful vocalizations such as grunting), or action (A) (movement such as playing with a toy or crawling). Verbal or vocal turns that were accompanied by nonverbal communication or actions were identified as either verbal or vocal modality.

\section{Results}

The mean number of turns and relative distribution of turn types for mothers and their children are reported on Table 1 . The frequency of turns was based on a total of 200 turns for each dyad, while the proportion scores for both mothers and children were based upon the total turns observed for each person. Two-way analyses of variance were computed on each of the variables to analyze for differences related to groups ( $N$ vs DS), developmental level (Younger vs Older), and the interaction between these factors. In general, there were no significant comparisons on any variables that were related either to developmental level or to the interaction between group and developmental level. However, there were several significant group effects, reported on Table 1, which indicate that normal and Down syndrome dyads differed in terms of both turn balance and turn type.

Group comparisons of the total turns for both mothers and children were significant $(p<.01)$, indicating that DS mothers had more turns and their children fewer turns than their normal counterparts. The magnitude of this difference can be illustrated by the mean difference in turns between mothers and their children, which was 6.4 turns for $\mathrm{N}$ dyads and 24.0 turns for DS dyads. This difference indicates that the turn imbalance for DS dyads was more than three times greater than for $\mathrm{N}$ dyads.

The analysis of turn type indicated that mothers of Down syndrome children had almost twice as many mands and only $4 / 5$ as 
TABLE 1

Means and Group Comparison on Mother and Child Turntaking Behavior

\begin{tabular}{lcrrrrrr}
\hline \hline & \multicolumn{3}{c}{ Down Syndrome } & \multicolumn{3}{c}{ Normal } \\
Variable & Younger & \multicolumn{1}{c}{ Older } & Total & Younger & Older & Total & $F^{*}$ \\
\hline Maternal Turns $^{\mathrm{b}}$ & 112.2 & 111.4 & 111.8 & 102.7 & 103.7 & 103.2 & $16.48^{* *}$ \\
Child Turns $^{\mathrm{b}}$ & 87.0 & 88.6 & 87.8 & 97.3 & 96.3 & 96.8 & $16.49^{* *}$ \\
Maternal Mand $^{\mathrm{n}}$ & 37.7 & 33.8 & 35.8 & 20.0 & 17.1 & 18.6 & $24.72^{* *}$ \\
Maternal Response & 24.0 & 22.7 & 23.4 & 28.3 & 29.6 & 29.0 & 2.95 \\
Maternal R-M & 36.8 & 43.2 & 40.0 & 50.2 & 51.4 & 50.8 & $15.06^{* *}$ \\
Maternal Unlinked & 1.5 & 0.4 & 1.0 & 1.5 & 2.2 & 1.8 & 2.49 \\
Child Mand & 8.7 & 8.0 & 8.4 & 16.1 & 11.6 & 13.9 & $9.27^{* *}$ \\
Child Response & 67.8 & 70.0 & 68.9 & 62.6 & 65.1 & 63.9 & 2.17 \\
Child R-M & 10.9 & 11.8 & 11.4 & 16.8 & 18.7 & 17.8 & $9.28^{* *}$ \\
Child Unlinked & 12.4 & 9.0 & 10.7 & 4.0 & 4.7 & 4.4 & $9.24^{* *}$ \\
\hline
\end{tabular}

$*_{\mathrm{p}}<.05$

$* * \mathrm{p}<.01$

${ }^{\mathrm{a}} \mathrm{F}$ are for comparisons of total groups

bTotal number of turns observed

'All type data are percentages of either the mother or child's total turns

many response-mands as mothers of normal children ( $p s<.01$ ). There were no significant differences between the groups of mothers in their proportions of response and unlinked turns. Among the children there were significant group differences in mands, responsemands, and unlinked turns (ps $<.01$ ). Down syndrome children had fewer mands and response-mands and more unlinked turns than normal children. Thus while DS mothers appear to be more directive than $\mathrm{N}$ mothers, DS children had a substantially higher proportion of turns that were unrelated to the interaction than did $\mathrm{N}$ children. $\mathrm{N}$ mothers had more turns that were chained to their children's behavior (e.g., R-M), and their children had a higher proportion of turns which required responses from their mothers (e.g., M).

There were no group differences observed in the communicative modality used by the mothers. $93.8 \%$ of turns of DS mothers were verbalizations, as compared to $91.4 \%$ verbalizations for $\mathrm{N}$ mothers. Although the two groups of children had been matched closely on Expressive Language Age, there were significant group differences in the modality of children's turns. DS children produced fewer meaningful nonverbal communications $(58.7 \%$ vs. $70.8 \%)$ and more meaningless vocalizations ( $33.8 \%$ vs. $18.5 \%$ ) than $\mathrm{N}$ children (ps<.01).
Because there were significant differences in the number of turns produced by the two groups of children, the frequencies of the four categories of maternal turn type were recalculated as a function of the total number of turns taken by children. This analysis yields an estimate of the rate at which mothers produced the four categories of turns as a function of the amount of interactional behavior produced by their children. The results of this analysis indicated that the two groups of mothers were almost identical in their rates of response $(D S=29.6 \% ; \mathrm{N}=$ $30.9 \%$ ), response-mand (DS $=51.0 \% ; \mathrm{N}=$ $54.3 \%$ ) and unlinked turns (DS $=1.2 \% ; \mathrm{N}=$ $1.9 \%$ ) in relation to their children's total behavior. However, the previous differences between the two groups of mothers in their rate of mands were accentuated by this analysis $(\mathrm{DS}=45.7 \% ; \mathrm{N}=19.8 \%, \mathrm{p}<.001)$. These findings suggest that the group differences in maternal response-mands are related to differences in the number of turns taken by their children, but that DS mothers are substantially higher in their rate of mands compared to $\mathrm{N}$ mothers even when differences in children's behavior are taken into account.

A series of correlations were computed to examine the relationship between mother and child conversational behavior. Since there were group differences in conversa- 
tional patterns, the correlations were computed separately for each group. As indicated on Table 3, only 2 of 24 correlations were significant for the $\mathrm{N}$ group, while 6 of 24 correlations were significant for the DS groups. For the $\mathrm{N}$ group infant total turns correlated negatively to maternal mands, and infant unlinked correlated positively to maternal unlinked. For the DS group infant total turns correlated negatively to maternal mands and positively to maternal response; infant response-mands correlated negatively to both maternal total and maternal mands but positively to maternal response; and infant unlinked correlated positively to maternal mands. Although both groups had significant negative relationships between infant total and maternal mands, infant total accounted for $83 \%$ of the variance of maternal mands among the DS group but only $31 \%$ of the variance of maternal mands among the $N$ group.

Intercorrelations were also computed be. tween various characteristics of conversational behavior both for mothers and for their children. For both groups of mothers there were positive correlations between mands and total turns $(r s=.56, p<.01)$, and negative correlations between mands and responses $(\mathrm{rN}=-.50, \mathrm{p}<.05 ; \mathrm{rDS} \doteq-.87, \mathrm{p}$ $<.01)$. It appears, therefore, that the more mothers manded, the more turns they took and the less they responded to their children. The only other significant correlations were between response-mand and response for $\mathrm{N}$ mothers $(\mathrm{r}=-.66, \mathrm{p}<.01)$ and between response-mand and mand for DS mothers $(r=-.55, p<.05)$. Intercorrela-

TABLE 2

Correlations between Mother and Infant Conversational Behavior for Normal and Down Syndrome Groups ${ }^{a}$

\begin{tabular}{lccccc}
\hline \hline Infant Conversational & & \multicolumn{4}{c}{ Mother Conversational Variables } \\
Variables & Total Turns & Mand & Response & Response & Unlinked \\
\hline Total Turns & & $-.91^{*}$ & $.74^{*}$ & \\
& & $-.56^{*}$ & & \\
Mand & & & & \\
Response & & & & \\
Response-Mand & -.49 & $-.57^{*}$ & .54 & $-74^{*}$ \\
Unlinked & & .48 & & & \\
\hline
\end{tabular}

${ }^{a}$ Underlined correlations are for Normal dyads: all other correlations are for Down syndrome dyads.

*Denotes $\mathrm{p}<.01$ : all other correlations are $\mathrm{p}<.05$.

TABLE 3

Intercorrelations of Conversational Behavior for Down Syndrome and Normal Infantsa

\begin{tabular}{|c|c|c|c|c|c|c|c|}
\hline Variables & Mand & Response & $\begin{array}{c}\text { Response } \\
\text { Mand }\end{array}$ & Unlinked & Verbal & Nonverbal & Action \\
\hline Total Turns & & & $.59 *$ & & & & \\
\hline Mand & & $-.72^{*}$ & & & -.49 & $-.66^{*}$ & \\
\hline Response & & & $-.64^{*}$ & $-.68^{*}$ & & $.61^{*}$ & $-.68^{*}$ \\
\hline Response Mand & & & & & $\begin{array}{l}.68^{*} \\
.54 \\
\end{array}$ & -.49 & \\
\hline Unlinked & & & & & & & $\begin{array}{l}.87 * \\
.98 * \\
\end{array}$ \\
\hline
\end{tabular}

${ }^{a}$ Underlined correlations are for Normal dyads; all other correlations are for Down syndrome dyads.

${ }^{*}$ Denotes $\mathrm{p}<.01$; all other correlations are $\mathrm{p}<.05$. 
tions for children's conversational behavior are reported on Table 3 . The pattern of significant relationships suggests that responsemands were associated with the highest levels of communicative behavior, unlinked turns were related to noncommunicative actions, and responses and mands were related to intermediate levels of communicative functioning.

\section{DISCUSSION}

The findings from this study indicate that there are substantial differences in the conversational patterns between mothers and Down syndrome children compared with those between mothers and normally developing children. Perhaps the most striking of these differences was related to the quality of communication of the two groups of children. Even though these children had been matched carefully on standardized measures of language and mental functioning, the Down syndrome children were inferior to the normal children on several conversational measures. Compared to normal children Down syndrome children were about $10 \%$ less active during the interaction, and $80 \%$ more of their turns were meaningless vocalizations. Normal children's superior quality of communication was also indicated by their higher proportion of mands and response-mands, both of which are indicative of their more active role in conversation (e.g., Kaye \& Charney, 1981). While mothers of Down syndrome children were as responsive to their children's communication as mothers of normal children, they were, nevertheless, more dominant communication partners as was indicated by their higher rates of both mands and turns. When differences in children's conversational activity were controlled, mothers of Down syndrome children manded 2.3 times more frequently than mothers of normal children.

There are two explanations for the conversational patterns observed between mothers and their Down syndrome children. The first is that the children are less active during the interaction because the mothers are more dominant; the second is that the mothers are more dominant because the children are less active. Although the design for this study is inadequate for deciding between these alter- native explanations, the data is more compatible with the notion that the inactivity of Down syndrome children caused their mothers to become more dominant. Two findings are particularly pertinent to this conclusion. The first is that mothers responded to the interactional behavior of their Down syndrome children at the same rate that mothers responded to the interactional behavior of their normal children. This finding is remarkable in view of the fact that Down syndrome children produced more meaningless behavior than did normal children. The second finding was related to the correlations between total infant turns and rate of maternal mands. In both groups the rate of maternal mands was high when children's rate of total turns was relatively low. This relationship was much more evident in the Down syndrome group, however, in which the number of turns taken by the children was both significantly lower than observed among normal children and considerably lower than $50 \%$ of the total dyadics turns. These same correlations also indicate that mothers of Down syndrome children had lower rates of mands when their children were more actively involved in the interaction.

Kaye \& Charney (1980) reported that mothers and normally developing children generally appear to engage in interaction on a 50:50 turn-taking basis. In this study, the Normal group approximated a 50:50 turn balance while the Down syndrome group had a 56:44 turn imbalance. It is possible that mothers of both groups of children manded, or requested that their children do something, as a strategy to correct imbalance in the interaction. Mothers may have reverted to this strategy more frequently with their Down syndrome children because these children were taking substantially fewer than $50 \%$ of the conversational turns. For a variety of reasons, however, mands may have been ineffective in achieving turn balance with the Down syndrome children. The mother's speed of manding may have been too great, or mothers may have asked their children to do things they either could not do or did not want to do. Additional studies are clearly needed to examine the response of Down syndrome and other mentally retarded children to maternal mands.

The major question addressed by this study is whether conversational patterns be- 
tween mothers and their Down syndrome children can account for the depressed language growth among this population. Communication theories of language development postulate that children develop language, at least partly, as a result of their actively engaging in reciprocal communication (Bruner, 1983). The data from this study indicate that Down syndrome children play a less active role while communicating with their mothers than do normal children. The pattern of communication adopted by mothers of Down syndrome children has the potential to sustain their children's disposition to passivity. Even though the strategy of manding appears to be a logical procedure for increasing children's active involvement, it may have the opposite effect of reinforcing the child's passivity. That is, when mothers increase their interactional and conversational dominance as their children's activity level decreases, the children may be learning that they can get more from their mothers by communicating less, and that their accepted role in communicative interaction is to have a low rate of interaction. As children's relative inactivity in communication becomes an established pattern, the likelihood that their rate of language acquisition is delayed may be enhanced.

The preceding explanation is clearly only speculative and remains to be tested. There are, however, at least two model intervention projects where the interactional behaviors identified in this study are the primary targets for change. In both ECO (Ecological Communication System) (MacDonald, Gillette, Bickley \& Rodriguez, 1984) and TRIP (Transactional Intervention Program) (Mahoney \& Powell, 1984) procedures have been developed for targeting patterns of turn-taking between parents and their mentally handicapped children. In both programs the goal is to balance patterns of turn-taking between parents and their children, reduce parental mands, and increase parental responses. Interactional balance is achieved by instructing parents to wait longer for their children to respond; while decreased mands and increased responses are achieved by asking parents to imitate their children's behavior and to follow their children's interests. Both programs have been able to achieve changes in parent-child interactional behavior, but there is not yet sufficient data to evaluate how such changes affect children's development.

\section{REFERENCES}

Bayley, N. (1969). Bayley scales of infant development. New York: The Psychological Corporation.

Bruner, J. S. (1974/75). From communication to language-a psychological perspective. Cognition, 3, 255-287.

Bruner, J. S. (1983). Child's Talk: Learning to use Language. New York: W. W. Norton.

Bzoch, K. R., \& League, R. (1970). The receptive-expressive emergent language scale for the measurement of language skills in infancy. Gainesville, FL: The Tree of Life Press.

Cunningham, C. E., Reuller, E., Blackwell, Jr., \& Deck, J. (1981). Behavioral and linguistic development in the interactions of normal and retarded children with their mothers. Child Development, 52, 62-70.

Kaye, K. \& Charney, R. (1980). How mothers maintain dialogue with two year olds. In Olson, D. (ed.), The social foundations of language and thought: Essays in honor of Jerome S. Bruner (pp. 144-162). New York: Norton.

Kaye, K. \& Charney, R. (1981). Conversational asymetry between mothers and children. Journal of Child Language, 8, 35-49.

Lenneberg, E. (1967). Biological foundations of language. New York: Wiley.

MacDonald, J. D., Gillette, Y., Bickley, M., \& Rodriguez, C. (1984). ECO: Ecological communication system. Columbus, Ohio: The Nisonger Center.

Mahoney, G. J. (1975). An ethological approach to delayed language acquisition. American Journal of Mental Deficiency, 80, 139-148.

Mahoney, G. J. (1983). Communication patterns between mothers and developmentally delayed infants. Paper presented at the annual meeting of the Society for Research in Child Development.

Mahoney, G. J. Finger, I. \& Powell, A. (1985). The relationship between maternal behavioral style and the developmental status of mentally retarded infants. American Journal of Mental Deficiency, 90, 350-355.

Mahoney, G. J., Glover, A., \& Finger, I. 
(1981). The relationship between sensorimotor development and language development among mentally retarded and nonretarded children. American Journal of Mental Deficiency, 86, 21-27.

Mahoney, G. \& Powell, A. (1984). The Transactional Intervention Program: Teacher's Guide. Woodhaven, Michigan: Woodhaven School District.

Mahoney, G. J., Seeley, P. (1976). The role of the social agent in language acquisition: Implications for language intervention. In N. R. Ellis (Ed.), International review of research in mental retardation (Vol. 8, pp. 57-103). New York: Academic Press.

Mahoney, G. \& Snow, K. (1983). The relationship of sensorimotor functioning to children's response to early language training. Mental Retardation, 21, 248-254.

Petersen, G., \& Sherrod, K. (1982). Relationship of maternal language to language development and language delay of children. American Journal of Mental Deficiency, 96, 391-398.

Rondal, J. A. (1978a). Developmental sentence procedure and the delay-difference question of language development of Down's syndrome children. Mental Retardation, 16, 169-171.

Rondal, J. (1978b). Maternal speech to nor- mal and Down's syndrome children matched for mean length of utterance. Monograph of the American Association on Mental Deficiency. Washington, DC: American Association on Mental Deficiency.

Shatz, M. (1981). On the mechanism of language acquisition: Can features of the communicative environment account for language acquisition? In L. Gleitman \& E. Wanner (Eds.), Language acquisition: The state of the art (pp. 106-133). New York: Cambridge University Press.

Snow, C. (1977). Mother's speech research: From input to interaction. In C. E. Snow \& C. A. Ferguston (Eds.), Talking to children: Language input and acquisition (pp. 1-37). Cambridge: Cambridge University Press.

Wells, G. (1981). Language as interaction. In Wells, G. (Ed.), Learning through interaction: The study of language development (pp. 3-21). Cambridge: Cambridge University Press.

Gerald Mahoney is an Associate Professor of Education at the University of Michigan, Ann Arbor, where Kathleen Robenalt recently graduated. 